\title{
TECHNOLOGICAL PROCESS, WORKING CONDITIONS AND HEALTH INJURIES TO WORKERS IN THE PRODUCTION OF EGGS AND POULTRY
}

\author{
I. Stoilova ${ }^{1}$, V. Birdanova ${ }^{1}$, D. Dekov ${ }^{2}$ \\ ${ }^{1}$ Department of Hygiene, Medical Ecology and Occupational Diseases, Medical University - Pleven, \\ Pleven, Bulgaria \\ ${ }^{2}$ Department of General and Forensic Medicine, Medical University - Pleven, Pleven, Bulgaria
}

\begin{abstract}
The production of eggs and poultry is an important sub-sector of the food industry in Bulgaria. It is characterized by long - standing traditions and significant development prospects. Technological processes include a number of operations related to poultry farming and the production of poultry meat and eggs.

Unfavorable factors of production leading to damage to the health of workers are microclimate, forced labor, monotonous work with repetitive working movements, noise, vibration, poisons and dust.

Leaders in the incidence of occupational diseases are peripheral nervous system, bone - muscle, respiratory and digestive systems injuries.

Necessary and possible are a number of measures to improve working conditions and prevent occupational accidents and diseases.
\end{abstract}

Key words: eggs and poultry, working conditions, occupational diseases.

\section{INTRODUCTION}

Eggs and poultry production is an important sub-sector of the agri-food industry of Bulgaria. Birds are raised in private farms and enterprises, whose field of operation is egg production and poultry production (1).

Extensive and intensive methods of poultry raising are employed.

\section{Extensive methods include:}

- Free range poultry raising

This is done in two ways:

- in small family farms to meet the needs of the family for eggs and poultry meat;

- in larger industrial poultry farms for production for the markets

According to the requirements of the European Union, free-range poultry raising farms should have fences and shelters for protection from predators and bad weather.

*Correspondence to: Stoilova I. Y., Department of Hygiene, Medical Ecology and Occupational Diseases, Medical University - Pleven, 1 Kliment Ohridski str, 5800 Pleven, Bulgaria, irena.stoilova444@abv.bg, mobile: +359887 182054 ,
There are advantages of free range raising: the birds can move freely, get more intensive exercise, can eat fresh grass. Also, aggression and cannibalism can be prevented.

The disadvantage of free range raising are associated with dangers of suffocation, scooping, pecking, less food and water for some of the birds, risk from infection with parasites, ticks, etc., exposure to predators and unfavorable weather factors.

\section{- Mobile field poultry raising}

This is done in small family firms. It is seasonal, and remnants of crops are used.

\section{- Camp-field poultry raising}

This production is stationary, and the birds are raised in a moveable hen-house where they can roost for the night. This method of raising allows utilizing both wastes from crops and other major agricultural products.

\section{Intensive poultry raising include:}

- Raising on thick permanent layers

The layer is made of various cover materials cut straw from grain cultures and cut or ground corn-cods. The basic characteristic of these materials is their hygroscopicity. 


\section{- Raising on elevated platforms}

Grates or nets are used, installed above the floor level, assembled with load-bearing pillars and covering wooden blocks.

\section{- Battery cage raising}

The birds are raised in batteries divided into separate cages. Battery raising allows growing more birds on an area unit. The birds are not in contact with manure and movement is limited. This way, less feed materials are needed and the heat produced reduces the costs for heating. Disadvantages of battery cage raising are more cracked and broken eggs, batteries are not costeffective and more metal material is needed. Besides, batter cage raising is considered inhumane and this is related to lower price of eggs.

\section{Technological processes in industrial poultry raising}

Poultry raising for meat (raising broiler chickens) is associated with weekly changes in the technological process because of the quick growth of the birds. The cycle takes eight weeks. The feed and water are hand-carried, walls are spayed with water to maintain humidity (70\%), cleaning the premises, collection of the dead chickens, monitoring and management of the equipment that maintain optimal temperature, feeding and watering. After the third week, working processes are fully automated.

Basic daily activities include maintaining the necessary humidity, cleaning and collection of dead chickens. When the chickens are 56 days old, they are manually caught by the workers, put in cages and transported to the slaughter house.

In egg production, there is separate space for the laying hens and a room for the workers equipped with a switchboard and automated conveyor for egg-collection. The space for laying hens houses about 10000 birds. The arrangement of the cages is designed in such a way as to allow positioning a conveyor belt for automated collection of the eggs $(2,1)$.

\section{Working conditions in industrial poultry farms}

- Working place microclimate

The working conditions are relatively favorable. Because of the low speed air-flow ( 0.004 to $0.2 \mathrm{~m} / \mathrm{sec})$, overheating is possible in the warm seasons.

- Dust

Certain operations, such as catching birds, lead to high dust content of the air (up to $18 \mathrm{mg} / \mathrm{m}^{3}$ ). The dust is mainly of organic origin, grossly dispersed, and consisting of food particles, feathers, straw, etc. (3).

- Chemical factors

- As a result of the living processes of the birds, carbon dioxide, ammonia and hydrogen sulphide are produced in concentrations above the limits.

- Noise

Noise is above the recommended levels near the machines that load the bunkers with feed mixes.

- Working hours

The working day is 8 hours, on one shift, which starts and ends at different times depending on the technological process.

The main working operations include feeding the birds, collection and sorting of eggs in boxes, collection of dead birds, cleaning and disinfection of the premises, and maintenance of optimal temperature. The average energy spent in poultry raising amounts to about 3.5 $\mathrm{kcal} / \mathrm{min}$, i.e. the physical strain associated with the job is moderate (4).

\section{AIM}

The aim of the study was to put into effect prevention and early diagnosing damages to health in people working in egg and poultry production by throwing light on the occupational hazards and already existing diseases.

\section{MATERIALS AND METHODS}

We investigated 78 workers working in an egg and poultry production plant in North Bulgaria. The infrastructure of the plant was modernized according to the European Union requirements with funding from the Special Accession Programme for Agriculture and Rural Development (SAPARD). Production methods employed raising on elevated platforms and battery cage raising. The participants were selected according to their job descriptions (5, 4).

The sources of information used were as follows: document for temporary incapacity for work, cards documenting prophylactic medical examinations and data for occupational traumas and diseases for the period 2015-2017. Statistical methods were used to analyze and evaluate morbidity leading to temporary incapacity for work, and comparison of standardized groups with benchmarking nosological groups. An integrated personality approach was applied to analyze the health status of the participants $(6$, $1,7,8)$. 
RESULTS AND DISCUSSION

We investigated 78 subjects - $33(42.3 \%)$

females and 45 (57.7\%) males.
STOILOVA I., et al.

The age range of participants was 21-60 years, the average being 43.08 years (Table 1).

Table 1. Distribution by age in years

\begin{tabular}{|l|l|l|l|l|l|}
\hline $21-30$ & $31-40$ & $41-50$ & $51-60$ & Over 61 & Total \\
\hline $9(11.5 \%)$ & $19(24.4 \%)$ & $24(30.8 \%)$ & $21(26.9 \%)$ & $5(6.4 \%)$ & $78(100 \%)$ \\
\hline
\end{tabular}

The distribution of participants by length of employment is presented on Table 2.

Table 2. Distribution by length of employment in years

\begin{tabular}{|l|l|l|l|l|l|l|}
\hline Up to $5-30$ & $6-10$ & $11-15$ & $16-20$ & $21-25$ & Over 25 & Total \\
\hline $8(10.3 \%)$ & $12(15.4 \%)$ & $20(25.6 \%)$ & $9(11.5 \%)$ & $15(19.2 \%)$ & $14(18 \%)$ & $78(100 \%)$ \\
\hline
\end{tabular}

The main occupations in the plant were poultry raiser, mechanic, packer, unskilled worker, technician and administrative worker.
Distribution by occupation is shown on Table 3.

Table 3. Distribution by occupation

\begin{tabular}{|l|l|}
\hline Poultry raiser & $33(42.3 \%)$ \\
\hline Packer & $14(17.9 \%)$ \\
\hline Technician & $12(15.4 \%)$ \\
\hline Mechanic & $6(7.7 \%)$ \\
\hline Unskilled worker & $5(6.4 \%)$ \\
\hline Administrative worker & $8(10.3 \%)$ \\
\hline Total & $78(100 \%)$ \\
\hline
\end{tabular}

The analysis of morbidity with temporary incapacity for work during the period investigated showed it was low (under 40\%). The overall morbidity was low as well, registered in 73 of the participants. Absenteeism was low - 593 working days per 100 participants. The average length of absence from work was 15.7 days per nosological unit. The results could be explained by the small average number of employees and the number of persons taking short or long sickness leaves (1).

Among the diseases leading to temporary incapacity for work, those affecting the peripheral nervous system ranked first, followed by diseases of the musculoskeletal system and connective tissue, diseases of the respiratory and gastrointestinal system, and metabolic diseases (Table 4).

Table 4. Distribution of diseases leading to temporary incapacity for work

\begin{tabular}{|l|l|}
\hline Diseases of the peripheral nervous system & $38 \%$ \\
\hline Diseases of the musculoskeletal system and connective tissue & $21 \%$ \\
\hline Diseases of the respiratory tract & $19 \%$ \\
\hline Diseases of the gastrointestinal tract & $11 \%$ \\
\hline Other & $11 \%$ \\
\hline Total & $100 \%$ \\
\hline
\end{tabular}

The results above can be attributed to the nature of work and the occupational risk involved (9). There are biological factors constant contact with the birds and products of their living processes, overstrain of the spinal column and extremities caused by compulsory work posture, psychosensory and psychosocial stress associated with the specificity of work, shifts, and exposure to chemicals.

Diseases detected at prophylactic medical examinations are presented in Table 5.
Accidents at work and occupational diseases were not registered during the study period. The morbidity registered was influenced by improper diet, tobacco smoking and problems in daily life (Table 6).

The low morbidity rates found at examination and the lack of occupation-related morbidity are probably due to providing working conditions, consistent with health and safety. Other factors include the young age of the workers (under 45 years) good communication with the general practitioners, etc. 
Table 5. Diseases registered at prophylactic examinations

STOILOVA I., et al.

\begin{tabular}{|l|l|}
\hline Diseases of the musculoskeletal system & 30 \\
\hline Diseases of the nervous system and sensory organs & 23 \\
\hline Cardiovascular diseases & 19 \\
\hline Diseases of the digestive system & 18 \\
\hline Diseases of the respiratory system & 16 \\
\hline Diseases of the endocrine system & 11 \\
\hline Diseases of the blood vessels & 10 \\
\hline Skin diseases & 7 \\
\hline Eye diseases & 7 \\
\hline Diseases of the urinary tract & 5 \\
\hline Gynecological diseases & 4 \\
\hline
\end{tabular}

Table 6. Harmful habits and additional burdens of daily life

\begin{tabular}{|l|l|l|}
\hline & Yes & No \\
\hline Harmful habits & $34(44 \%)$ & $44(56 \%)$ \\
\hline Additional burdens of daily life & $25(32 \%)$ & $53(68 \%)$ \\
\hline
\end{tabular}

\section{CONCLUSIONS}

- Workers employed in poultry and egg production are exposed to a variety of hazards during work (biological, physical, and chemical factors, dust and overstrain).

- Diseases of the peripheral nervous system, of the musculoskeletal system and the gastrointestinal system prevail. Probably, morbidity rates can be also influenced by factors not related to work, such as smoking habits, problems in daily life, among others.

\section{RECOMMENDATION FOR PROPHYLAXIS}

- Strict criteria should be applied for selection of employees, based on preliminary medical check ups before hiring workers with health problems that are contraindicated for poultry and egg production processes.

- Scheduled medical check ups should carry out screening and make early diagnosis of diseases related to employment in poultry and egg production.

- The persons with detected abnormalities should be timely diagnosed, treated and referred for appropriate labor readjustment.

\section{REFERENCES}

1. Semerdjiev, V et al. Poultry raising, Enyovche, Sofia, 2006 (in Bulgarian)

2. Izmerov et al. Guidelines in Occupational Medicine, Moscow, 1987 (in Russian)
3. Grancharova, G, Hristova, P. Medical statistics, Publishing Centre, Medical University - Pleven, 2011 (in Bulgarian)

4. Lukanov, $\mathrm{M}$ et al. Occupational hygiene in major branches of production, Sofia, 1978 (in Bulgarian)

5. Borisov, V et al. Health and health protection of workers, Sofia, 1984 (in Bulgarian)

6. Popov, B et al. Hygiene, nutrition and occupational diseases, Sofia, 2009 (in Bulgarian)

7. Stefanova, P, Velkova A, Simeonova Y, Kamburova M, Georgieva S, Deyanov S, Kostadinov S Selecting risk groups of the population as part of prophylactic activities of general practitioners, $23^{\text {rd }}$ Scietific conference, Stara Zagora, 6-7.06.2013, ISSN 1314 -4111 International Science and technology On-line Journal, Published by Bulgarian Union of Scientists - Stara Zagora, Volume III, Number I, 2013, p. 351-355

8. Tsacheva, S, Standard methods of analysis of the health status of ensured employees, National Center of Hygiene, Sofia, 2001 (in Bulgarian)

9. Alexieva, T et al. Occupational pathology, Sofia, 1982 (in Bulgarian)

10.Selvin S., Statistical analysis of epidemiological data, New York, Oxford,1991 